Raúl Silva Castro

\title{
Cuestión de palabras...
}

ENERALMENTE se habla de las palabras con cierto desprecio. «Cuestión de vocablos» - se dice, en tono despectivo, cuando en una discusión los antagonistas no pueden ponerse de acuerdo sobre un matiz ideológico que a veces es muy importante. En el fondo lo más serio es asimple» cuestión de palabras. Convertido el lenguaje en signo o, como quieren otros filósofos que han tratado de su origen, signo desde el primer instante de su vida, cada palabra de las que lo componen encierra un contenido ideal, algo que o existe materialmente o es mera concepción mental. Por eso son las palabras las que dividen a los hombres y sobre ellas se forman odios, diferencias insaivables y conflictos sin fin. A su vez, el estudio de las palabras es una parte fundamental de las disciplinas a que se somete el individuo. En el fondo la gran mayoría de los asuntos que preocupan a la humanidad depende sólo de saber o no a ciencia cierta el contenido de las palabras empleadas en traducirlo, sus límites y las leyes que rigen sus relaciones recíprocas.

Desde el punto de vista literario, la palabra asume un - cariz de importancia exclusiva. Ella lo es todo en la li- 
teratura. ¿No es verdad que la vieja distinción entre el fondo y la forma es algo antojadizo y que puede ser reducido perfectamente al solo estudio de las palabras? Las palabras son algo más que juguetes; no son lo deleznable y adjetivo de la literatura, sino el alma misma de ésta. Y aun pasando al campo de la estética, las palabras son también el origen del criterio con que se puede juzgar la obra literaria.

Tratando de las palabras, una de las primeras peculiaridades con que se tropieza es la existencia de la moda, tan marcada en éste como en otros sectores de la vida humana. Hay palabras que están de moda así como se ponen de moda un traje, un peinado, un color y una manera de vivir. Y esas palabras tienen un día efímero de gloria en que todos se las disputan para su uso, y luego pasan y se hunden en la sombra, tal vez para siempre.

Cuando esas palabras se mantienen más tiempo del que sería discreto en el uso constante y tenaz de la mayoría, entonces llegan a ser alugares comunes». Pero lugares comunes son también las alianzas de dos o más términos - generalmente un sustantivo y un adjetivoque concurren para formar un solo signo mental. Entre los lugares comunes que nos ofrece nuestra literatura actual, podemos, por ejemplo, destacar «por todos los caminos». Expresión generalmente usada en poesía, raro es el poeta que no haya caído en su lazo fatal. A fuerza del uso inmoderado, cualquier expresión pierde el vigor original que pudo tener y llega a acusar simplemente falta de imaginación en quien la emplea. De un poeta que diga aún en sus versos spor todos los ca- 
minos, bien podemos pensar cosas tristes y poco halagadoras para su poesía.

Cada época tiene, pues, sus palabras de moda y sus lugares comunes que le son propios. $\mathrm{El}$ modernismo con que se abrió paso en América el siglo presente, trajo un buen surtido de ambas cosas. De una parte muchas palabras que hasta entonces dormian olvidadas en obscuros vocabularios o en libros que nadie leía ya y hasta algunas que no constaban en unos ni en otros, entraron al dominio de la literatura más selecta para pasar luego al de la prensa y a la conversación. Fueron en su tiempo palabras de moda que el uso demasiado frecuente gastó y redujo lamentablemente. Hoy ya son simples lugares comunes. Literatos de poca monta, obscuros grafómanos son los únicos que persisten en usarlas sin tasa ni medida.

Pero cada uno de estos hechos trae aparejados algunos problemas tal vez menores, pero siempre importantes dentro del marco de este asunto. Veamos, por ejemplo, el cambio de sentido.

A fuerza de usar continuamente una expresión, pueden producirse varios fenómenos que tocan a su sentido. Si las personas que las emplean saben bien lo que ella significa, el cambio de sentido se deberá al cambio de sensibilidad que de tiempo en tiempo sufren los hombres, considerados en conjunto. Si la palabra elegida pertenece al número de las que sólo puede emplear correctamente una minoría, entonces el cambio de sentido se efectúa según ciertas leyes que no siempre son lógicas. Ejemplos: el sentido actual y generalizado de nimio se ha calcado, por simple parecido fonético, sobre el de mínimo. La 


\section{Cuestión de palabras...}

palabra clepsidra ha sido muy empleada, generalmente por los poetas, para significar un aparato que sirve para medir el tiempo; en una ocasión hemos visto un dibujo en que figuraba un reloj de arena, el cual era llamado clepsidra por la persona que había hecho una leyenda sobre el grabado aludido. En su sentido recto de areloj de agua • lo usó el malogrado Domingo Gómez Rojas en uno de sus más hermosos poemas.

El fenómeno contrario al cambio de sentido es la resurrección de ciertos vocablos que sufren eclipses más o menos largos, a veces hasta seculares. El movimiento modernista que hemos ya citado, se valió en muchas ocasiones de palabras resurrectas para traducir sensaciones novedosas, para las cuales un lenguaje literario que obedecía a una sensibilidad pretérita, no tenía signos apropiados. Uno de los antecedentes del modernismo, el parnasianismo francés, fué el que le dió el ejemplo, debido a su intensa admiración, a su amor, será mejor decir, por las civilizaciones clásicas en que encontró inspiración frecuente. Largas listas de palabras podrían extraerse de obras de los modernistas hispano-americanos, y en ellas se verían muchas que yacían enterradas en libros clásicos ya muy olvidados. No menor sería la de adaptaciones de palabras de origen latino y griego, realizadas por Rubén Darío, precursores y discípulos.

Entre tanto los neologismos verdaderos son muy escasos. Muchos de los que parecen serlo son simples resurrecciones. Otras palabras nos sorprenden, no por ellas mismas, sino por sus conexiones, ya sea porque han cambiado de sentido, ya porque el régimen de ellas ha variado. Neologismos propiamente tales son muy ex- 
traños. Por ejemplo, nuestro poeta adolescente que escribió:

\section{Una esperanza romancera}

no consiguió fijar un neologismo, sino un vulgar y simple disparate. Origen evidente de él puede ser la obtigación, no siempre muy fielmente seguida por él, de la rima; pero sea lo que fuere, el disparate subsiste a pesar de todo.

Es en cambio un neologismo interesante y que responde a una necesidad de la expresión literaria actual, el verbo engrisecer que emplea Pablo Neruda en un poema en prosa publicado hace poco en «El Mercurio». Formado a semejanza de atardecer, de enmudecer, etc., reúne todas las condiciones exigidas para vivir. No se puede decir lo mismo del adjefivo lafiente que el mismo Neruda emplea en el poema número 4 de su libro "Veinte poemas de amor». No es que latiente no tenga en realidad las condiciones vitales necesarias, sino que denota un matiz, fino hasta el exceso, de diferencia respecto de lafente, la forma consagrada y vulgar. Se nos ocurre también que latiente puede ser una simple resurrección, acaso inconsciente, porque tenemos la idea de haberlo encontrado en una obra clásica de cuyo nombre y autor no tenemos memoria. Otros neologismos apreciables de Neruda son los siguientes fulgurecer (en - Veinte poemass), análogo a engrisecer y paralelo al vocablo corriente que es fulgurar; rojedad (en ¿Crepusculario»), que puede reemplazar con ventaja a rojez, único sustantivo que denota la cualidad de rojo; volofear (en -Crepusculario»), que forma grado con el ya 
conocido revolofear, y algunas otras palabras de menor importancia.

En el reciente libro de Pedro Prado, «Un juez rural», encontramos también algunos vocablos que merecen atención. Veamos, por ejemplo, el adjetivo hoyado, desprendido no de huella como pudiera creerse, y corrompido en su ortogralía, sino sacado de hoyo. Hoyado es, en el libro, un camino lleno de baches. Luego encontramos un verbo nacido de un advervio; encimar en el sentido de superar, estar sobre algo. $\mathrm{Y}$ un hermoso adjetivo que viene a enriquecer la lengua jurídica con un término que evita circunloquios más o menos dilatados. En efecto, «desistente» llama Prado al querellante que se desiste de la acción entablada contra un tercero. Fuera de estos vocablos, este libro nos ofrece también muchos y muy sabrosos chilenismos, algunos de ellos verdaderamente característicos.

Estas palabras nuevas y estas nuevas alianzas que dan un aspecto insólito al idioma, aun cuando él se valga generalmente todavía de viejísimos resortes, sugieren el pensamiento de hacer periódicamente un arqueo de esta riqueza fluctuante. Cada palabra tiene su encanto peculiar. Gourmont, profundo conocedor de su lengua, asentó el principio de que la palabra aisladamente considerada tiene su propia belleza, «desprendida-dice-de la imagen o de la idea que contiene». La palabra agrada por su encanto fonético, por su resonancia íntima, por las relaciones inconscientes que despierta en el espíritu. Para apreciarla y gustarla no hay necesidad de ejercer sobre ella el análisis gramatical o filosófico a que nos arrastran los diccionarios. Sin sujeción a normas que pudiéramos 
llamar técnicas, la palabra adquiere la plenitud de sus valores en nuestro espíritu desprendido de toda prevención. Así hemos llegado a un concepto estético que es interesante fijar y que se debe casi por entero a Gourmont, ya que antes de él las palabras valían sólo como signos y ligadas al cinturón estrecho de la lógica.

Los hombres amantes de la idea escueta expresada en feas palabras seguirán menospreciando a éstas y diciendo como hasta ahora de lo que no vale o de lo que quieren que no valga, que es «cuestión de palabras». Pero, a pesar de ellos, las palabras siguen siendo lo fundamental, lo que más pesa, el elemento esencial de la literatura y algo de lo que más vale en la vida. Por eso mismo debemos exigir más respeto para ellas, cariño, entusiasmo y discreción en su empleo. Las palabras valen demasiado para ser dilapidadas como las dilapidamos nosotros y son demasiado bellas para emplearlas al desgaire como lo hacen muchos. Son la expresión suprema de la inteligencia del hombre, y como tal debemos lomarlas.

Santiago, octubre de 1924.

RAÚl SILVA CASTRO. 